\title{
Cell Type-Specific Circuits of Cortical Layer IV Spiny Neurons
}

\author{
Dirk Schubert, ${ }^{1}$ Rolf Kötter, ${ }^{1,2}$ Karl Zilles, ${ }^{1,3}$ Heiko J. Luhmann, ${ }^{4}$ and Jochen F. Staiger ${ }^{1}$ \\ ${ }^{1}$ C. \& O. Vogt Institute for Brain Research, ${ }^{2}$ Institute of Morphological Endocrinology and Histochemistry, University of Duesseldorf, D-40001 Duesseldorf, \\ Germany, ${ }^{3}$ Institute of Medicine, Research Centre Juelich, D-52425 Juelich, Germany, and ${ }^{4}$ Institute of Physiology and Pathophysiology, University of \\ Mainz, D-55128 Mainz, Germany
}

Sensory signal processing in cortical layer IV involves two major morphological classes of excitatory neurons: spiny stellate and pyramidal cells. It is essentially unknown how these two cell types are integrated into intracortical networks and whether they play different roles in cortical signal processing. We mapped their cell-specific intracortical afferents in rat somatosensory cortex through a combination of whole-cell patch-clamp recordings and caged glutamate photolysis. Spiny stellate cells received monosynaptic excitation and inhibition originating almost exclusively from neurons located within the same barrel. Pyramidal cells, by contrast, displayed additional excitatory inputs from nongranular layers and from neighboring barrels. Their inhibitory inputs originated, as for spiny stellate cells, mainly from neurons located in the same barrel. These results indicate that spiny stellate cells act predominantly as local signal processors within a single barrel, whereas pyramidal cells globally integrate horizontal and top-down information within a functional column and between neighboring barrels.

Key words: barrel cortex; layer IV; pyramidal cell; spiny stellate cell; functional connectivity; excitatory inputs; inhibitory inputs; morphology; electrophysiology; biocytin; caged glutamate; somatosensory; slices

\section{Introduction}

In the primary somatosensory cortex of rodents, layer IV neurons are arranged in discrete clusters (barrels) (Woolsey and Van der Loos, 1970) that receive a topographically organized input from their respective principal whisker on the contralateral side of the face (via the whisker-to-barrel pathway) (Jones and Diamond, 1995). From layer IV the information is transmitted within a functional barrel-related column predominantly to layers II/III and subsequently to infragranular layers (Armstrong-James et al., 1992; Petersen and Sakmann, 2001). In addition to these vertical intracolumnar pathways, neuronal activity is transmitted via horizontal projections in supragranular (Feldmeyer et al., 2002) as well as infragranular layers (Feldmeyer and Sakmann, 2000; Schubert et al., 2001a) to the neighboring barrel-related column. Such transcolumnar interactions may be a primary mechanism for the generation of multiwhisker receptive fields (Simons, 1978; Simons and Carvell, 1989; Armstrong-James et al., 1992).

Circuits within and between barrel-related columns are not well understood. Neuroanatomical (Kim and Ebner, 1999) as well as recent in vitro and in vivo electrophysiological studies (Goldreich et al., 1999; Laaris et al., 2000; Petersen and Sakmann, 2000) seem to indicate that a direct barrel-to-barrel pathway does not exist to a significant extent. Thus, thalamocortical connections (Petersen and Diamond, 2000) as well as horizontal interactions in supragranular and infragranular layers (Petersen and

Received Dec. 17, 2002; revised Jan. 21, 2003; accepted Jan. 22, 2003.

This study was supported by the C. \& 0. Vogt-Institut fuer Hirnforschung GmbH, the "Gertrud Reemtsma Stiftung," and Deutsche Forschungsgemeinschaft Grants Lu 375/3 to H.J.L. and Sta 431/5-1 to J.F.S. We thank Ulrich Opfermann-Emmerich for excellent technical assistance and Dr. Ritchie Brown for critically reading this manuscript.

Correspondence should be addressed to Dirk Schubert, C. \& 0. Vogt Institute for Brain Research, Heinrich-HeineUniversity Duesseldorf, P.0. Box 101007, D-40001 Duesseldorf, Germany. E-Mail: schubd@uni-duesseldorf.de. Copyright $\odot 2003$ Society for Neuroscience $\quad 0270-6474 / 03 / 232961-10 \$ 15.00 / 0$
Sakmann, 2001) were suggested to assemble multiwhisker receptive fields.

Another unresolved question is in which way the morphologically heterogeneous excitatory neurons in layer IV, i.e., spiny stellate cells and pyramidal cells, contribute to intracortical circuits. These two main morphological groups coexist not only in layer IV of the rat barrel cortex (Simons and Woolsey, 1984) but also in other sensory cortices of various species (Jones, 1975; Tarczy-Hornoch et al., 1998; Smith and Populin, 2001; Yabuta et al., 2001). A recent in vivo study indicates that, in fact, spiny stellate and pyramidal cells within barrels show different response dynamics after whisker deflection (Brecht and Sakmann, 2002).

To map the intracolumnar and transcolumnar synaptic inputs to barrel-related neurons, we performed whole-cell recordings from visually identified and biocytin-labeled spiny neurons in layer IV of rat barrel cortex in vitro. Presynaptic neurons were stimulated by focal caged glutamate photolysis (Callaway and Katz, 1993; Kötter et al., 1998; Sawatari and Callaway, 2000; Staiger et al., 2000; Schubert et al., 2001a), and the resulting monosynaptic postsynaptic potentials were used to construct detailed maps of the functional synaptic inputs onto layer IV spiny stellate and pyramidal neurons.

Our data indicate that layer IV barrels do not entirely function as an array of independent parallel processors (Goldreich et al., 1999) but rather possess cell type-specific circuits allowing significant intracolumnar feedback and even direct barrel-to-barrel interactions. Feedback may allow a top-down modulation of layer IV circuits during sensory learning (Diamond et al., 1994; Harris et al., 2001), whereas horizontal pathways may provide a mechanism for an early integration of multiple discrete sensory signals into a unified neuronal percept (Gilbert et al., 1996). 
Part of this study has been published previously in abstract form (Schubert et al., 2001b).

\section{Materials and Methods}

Slice preparation and chemicals. Coronal slices from rat somatosensory cortex containing the barrel cortex (Paxinos and Watson, 1998) were prepared by standard methods (Schubert et al., 2001a). Male Wistar rats (postnatal days 18-22) were deeply anesthetized with enflurane and decapitated. Blocks of tissue containing the barrel cortex were excised, quickly removed from the skull, and stored in ice-cold artificial CSF (ACSF) oxygenated with carbogen $\left(95 \% \mathrm{O}_{2} / 5 \% \mathrm{CO}_{2}\right)$. Normal ACSF consisted of (in mM): $124 \mathrm{NaCl}, 1.25 \mathrm{NaH}_{2} \mathrm{PO}_{4}, 26 \mathrm{NaHCO}_{3}, 1.6 \mathrm{CaCl}_{2}$, $1.8 \mathrm{MgCl}_{2}, 3 \mathrm{KCl}, 10$ glucose, at $\mathrm{pH}$ 7.4. To block synaptic transmission, modified ACSF containing $0.2 \mathrm{~mm} \mathrm{CaCl}_{2}$ and $4 \mathrm{~mm} \mathrm{MgSO}_{4}$ (low $\mathrm{Ca}^{2+}$ / high $\mathrm{Mg}^{2+} \mathrm{ACSF}$ ) was used. The tissue block was glued to the chilled platform of a Vibratome (Series 1000; TPI, St Louis, MO) and submerged in ice-cold carbogenated ACSF. Slices of $300 \mu \mathrm{m}$ nominal thickness were cut and incised along the midline to separate the hemispheres. The slices were stored in an incubation chamber containing carbogenated ACSF at $34^{\circ} \mathrm{C}$ for at least $1 \mathrm{hr}$. Slices were then transferred to the recording chamber and submerged in ACSF at a flow rate of $\sim 1 \mathrm{ml} / \mathrm{min}$ at $32^{\circ} \mathrm{C}$. Caged glutamate [L-glutamic acid, $\gamma$-( $\alpha$-carboxy-2-nitrobenzyl $)$ ester; Molecular Probes, Eugene, OR] was dissolved in ACSF and added to the circulating ACSF, resulting in a $1 \mathrm{~mm}$ concentration.

Identification of layer IV spiny neurons. Slices were placed in a fixedstage submerged chamber under an upright microscope (Axioskop FS; Carl Zeiss, Göttingen, Germany) fitted with a $2.5 \times$ and $40 \times$ waterimmersed objective ( $40 \times / 0.75 \mathrm{~W}$; Olympus, Hamburg, Germany) (Staiger et al., 2000). The barrel field was visualized at low magnification under bright-field conditions (see Fig. 1), and a target region within a layer IV barrel was selected for cellular recording. Individual neurons were visually identified at $40 \times$ magnification using infrared enhanced quarter-field illumination.

Electrophysiology. Whole-cell patch-clamp recordings from layer IV spiny neurons were performed in current-clamp mode using patch pipettes $(4-6 \mathrm{M} \Omega$ ) fabricated from borosilicate glass capillaries $(1.5 \mathrm{~mm}$ outer diameter, $1.16 \mathrm{~mm}$ inner diameter; Science Products, Hofheim, Germany) on a PP-830 puller (Narishige, Tokyo, Japan). Pipettes were filled with (in mM): $13 \mathrm{KCl}, 117 \mathrm{~K}$-gluconate, $10 \mathrm{~K}$-HEPES, $2 \mathrm{Na}_{2} \mathrm{ATP}$, $0.5 \mathrm{NaGTP}, 1 \mathrm{CaCl}_{2}, 2 \mathrm{MgCl}_{2}, 11 \mathrm{EGTA}$, and $1 \%$ biocytin. After obtaining a stable seal of $>1 \mathrm{G} \Omega$, the whole-cell configuration was achieved by gentle suction. Data were not corrected for the junction potential. A bipolar tungsten electrode placed in deep layer VI was used for electrical afferent stimulation $(200 \mu \mathrm{sec}, 0.1 \mathrm{~Hz})$.

Scanning of glutamate-evoked activity. The setup and experimental procedures for photolysis of caged glutamate have been described previously (Schubert et al., 2001a). For local stimulation, UV light pulses from a Xenon arc lamp (TILL Photonics, Planegg, Germany) were focused on $50 \times 50 \mu \mathrm{m}$ large areas. The illumination intensity was calibrated by a circular linear-wedge neutral density filter $\left(D_{\mathrm{r}}=0.0-2.0\right)$ (Melles Griot, Irvine, $\mathrm{CA}$ ) to a value that ensured action potential generation only on perisomatic photostimulation (Schubert et al., 2001a). In addition to layer IV spiny neurons $(n=40)$, also other neurons in layers II/III, IV, V, and VI $(n=61)$ were recorded and stimulated at the resting membrane potential $\left(V_{\mathrm{rmp}}\right)$ of the cell. Action potentials could not be elicited by photostimulation at distances $>100 \mu \mathrm{m}$ from the soma in any of these control experiments. While the synaptic connectivity was mapped, the cell was held at a potential $\left(V_{\text {hold }}\right)$ of $-60 \mathrm{mV}$ in current-clamp mode to reveal hyperpolarizing inhibitory synaptic inputs. The intrinsic properties of the recorded cells were controlled before and after termination of each map.

Data acquisition and analysis of glutamate-induced activity. The signals were amplified (SEC-05L; npi-electronics, Tamm, Germany), filtered at $3 \mathrm{kHz}$ and digitized using an ITC-16 interface (Instrutech, Port Washington, NY). Data were recorded, stored, and analyzed with PC-based software (TIDA 4.1 for Windows; Heka Elektronik, Lambrecht, Germany). After recording, slices were photographed in the bath chamber to document the topography of barrel-related columns and layers as well as the position of the recording and stimulating electrode.
Table 1. Morphological and electrophysiological properties of layer IV spiny neurons

\begin{tabular}{lcc}
\hline Morphological properties & Spiny stellate cells $(n=17)$ & Pyramidal cells $(n=11)$ \\
\hline Soma area $\left(\mu \mathrm{m}^{2}\right)$ & $173 \pm 34$ & $169 \pm 52$ \\
Number of primary dendrites & $4.2 \pm 1.8$ & $4.2 \pm 1.1$ \\
Number of dendritic ends & $22.4 \pm 5.5$ & $23.1 \pm 4.3$ \\
Mean total length of dendrites & & \\
$\quad(\mu \mathrm{m})$ & $1992 \pm 371$ & $2493 \pm 741$ \\
Mean length of apical dendrite & & \\
$\quad(\mu \mathrm{m})$ & & $916 \pm 384$ \\
\hline Electrophysiological properties & Spiny stellate cells $(n=28)$ & Pyramidal cells $(n=18)$ \\
\hline$V_{\text {rmp }}(\mathrm{mV})$ & $-66.4 \pm 4.0$ & $-65.9 \pm 4.5$ \\
$R_{\mathrm{m}}(\mathrm{M} \Omega)$ & $194 \pm 64$ & $180 \pm 41$ \\
Firing pattern & $\mathrm{IB}, n=15 ; \mathrm{RS}, n=13$ & $\mathrm{IB}, n=10 ; \mathrm{RS}, n=8$ \\
IB first-ISI (msec) & $6.7 \pm 0.8$ & $6.9 \pm 1.0$ \\
IB second-ISI (msec) & $13.0 \pm 4.2$ & $15.7 \pm 10.8$ \\
RS first-ISI (msec) & $20.8 \pm 12.4$ & $26.1 \pm 4.5$ \\
RS second-ISI (msec) & $50.8 \pm 10.8$ & $49.8 \pm 12.5$ \\
\hline
\end{tabular}

$\mathrm{IB}$, Intrinsically burst spiking; $\mathrm{RS}$, regular spiking; ISI, interspike interval. Data are means \pm SD.

To distinguish between flash-induced activity and spontaneous activity, integral values of all spontaneous events within a time window of 150 msec were determined for each cell. The highest integral value of spontaneous activity obtained in 20 control recordings for each cell was set as the cell-specific activity threshold. These control recordings were performed directly before mapping in ACSF containing caged glutamate without preceding photostimulation. Because inhibitory spontaneous activity was very rare, only integrals of excitatory spontaneous events were calculated. To identify glutamate-induced activity, integral values of all excitatory events after photostimulation in the same time window were calculated. Only activity that exceeded the cell-specific activity threshold was accepted as a glutamate-induced response. All integral values of glutamate-induced responses were corrected by the value of the cell-specific activity threshold.

Glutamate-induced responses were analyzed and superimposed on the respective sites of the slice photomicrographs. Statistical analysis was performed using multivariate ANOVA with post hoc pairwise comparisons (Bonferroni corrected) and unpaired two-tailed Student's $t$ test (SPSS 9; SPSS Inc., Chicago, IL). Data are presented as mean \pm SD.

Histological procedures. After recording, slices were fixed in phosphatebuffered solution containing $4 \%$ paraformaldehyde at $4^{\circ} \mathrm{C}$ for $24 \mathrm{hr}$. For visualization of the biocytin-filled neurons, slices were processed using a previously described protocol (Angulo et al., 1999). To visualize the barrel field, slices were also subjected to cytochrome oxidase histochemistry. Reconstruction and morphological analysis of the biocytin-labeled neurons were made using a Nikon Eclipse 800 (Nikon, Ratingen, Germany) attached to a computer system (Neurolucida; Microbrightfield Europe, Magdeburg, Germany). Soma area, number of primary dendrites, number of dendritic ends, total length of the dendrites, and length of the apical dendrite were determined for all layer IV spiny neurons (see Table 1). Data were not corrected for tissue shrinkage. The reconstructed cells were superimposed onto the photomicrograph of the native slice using standard graphics software.

\section{Results}

In the present study, a combination of whole-cell patch-clamp recording, topographic mapping of glutamate evoked activity, and subsequent morphological somatodendritic reconstruction was used to investigate the functional connectivity of layer IV spiny neurons in coronal slices of rat barrel cortex (Fig. 1). All investigated neurons were localized within a barrel. The dimensions of the respective barrels were first visually determined in microphotographs of living unstained slices and then confirmed in the histologically processed cytochrome oxidase-stained slices (Fig. 1a,b). 

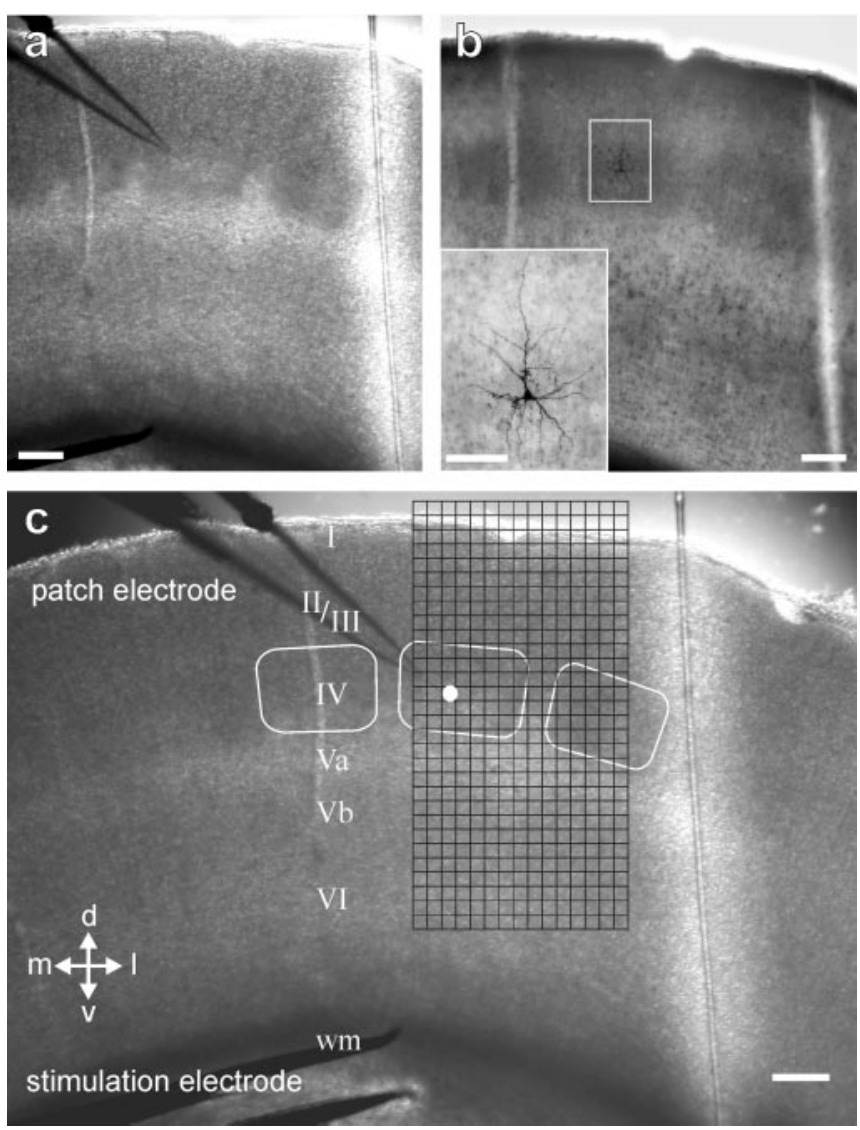

Figure 1. Experimental setup for whole-cell recording in layer IV and local caged glutamate photolysis. Photomicrographs of a coronal slice of the rat somatosensory cortex taken directly after an experiment with recording and stimulation electrodes $(a, c)$ and after histological processing $(b)$. $a$, Barrel field in the living, unstained slice at low magnification and the same section after staining for biocytin and cytochrome oxidase (b). The biocytin-labeled layer IV spiny stellate cell is shown enlarged in the inset. c, Position of the recorded layer IV spiny stellate cell (white dot) and extent of the region stimulated by local photolysis of caged glutamate (grid). At $10 \mathrm{sec}$ intervals, 450 fields of $50 \times 50 \mu \mathrm{m}$ in size were stimulated in sequence covering all cortical layers and at least two barrel-related columns. White frames highlight the layer IV barrels located within and near the investigated area. Roman numerals indicate cortical layers. Scale bars: $a-c, 200 \mu \mathrm{m} ; b$, inset, $100 \mu \mathrm{m}$.

\section{Morphological and electrophysiological classification of layer IV spiny neurons}

According to their somatodendritic morphology, we classified the biocytin-stained layer IV neurons as (1) spiny stellate cells ( $n=28$; reconstructed, $n=17)$ and (2) pyramidal neurons $(n=$ 18 , including 8 star pyramidal cells; reconstructed, $n=11$ ) (Table 1 ). The basic property of spiny stellate cells was the confinement of their dendritic tree to layer IV and the absence of an apical dendrite (Fig. 2a). Between two and nine primary dendrites emerged from the soma and bifurcated into several higher-order dendrites. In contrast to spiny stellate cells, pyramidal neurons possessed an apical dendrite, which extended out of the barrel into the supragranular layers without forming an extended terminal tuft (Fig. 2b), and two to five primary nonapical dendrites emerged from the soma.

Analysis of the electrophysiological properties of spiny stellate and pyramidal cells revealed comparable passive intrinsic membrane properties. However, their active membrane properties revealed two different types of action potential firing patterns ( $\mathrm{Ta}-$ ble 1). In agreement with previous studies (Chagnac-Amitai and Connors, 1989; Feldmeyer et al., 1999) regular spiking (RS) neu- rons were found in both morphologically identified cell classes (Table 1). After injection of suprathreshold depolarizing current pulses at resting membrane potential, RS cells fired regular trains of single action potentials with an average first interspike interval (first-ISI) of $22.9 \pm 10.1 \mathrm{msec}$ and a second interspike interval (second-ISI) of $50.4 \pm 11.2 \mathrm{msec}(n=22)$ (Fig. $2 c)$. Intrinsically burst spiking (IB) (Connors and Gutnick, 1990) cells, characterized by an initial high-frequency burst of usually three action potentials (first-ISI, $6.8 \pm 0.9 \mathrm{msec}$; second-ISI, $14.1 \pm 7.4 \mathrm{msec}$; $n=25$ ) (Fig. $2 d$ ) were also identified in both cell groups. Mean first-ISI as well as second-ISI values were significantly shorter in IB cells than in RS neurons $(p<0.01)$. Correlation of first-ISI with second-ISI values revealed two clusters for each type of action potential firing pattern, i.e., RS versus IB (Fig. 2e). However, spiny stellate and pyramidal cells were distributed nearly equally among these clusters, resulting in no correlation between the morphology of layer IV spiny cells and their intrinsic firing pattern.

Orthodromic stimulation in deep layer VI evoked a strong postsynaptic inhibition in spiny neurons. In all cells, orthodromic stimulation in deep layer VI elicited an EPSP, which was followed by a fast IPSP in 26 of 28 cells tested (Fig. $2 f$, asterisk). In 15 of 28 cells the fast IPSP was also followed by a slow IPSP (Fig. $2 f$, double asterisk).

\section{Neuronal activity elicited by local photolysis of caged glutamate}

Focal photolysis of caged glutamate induced two types of activity in the recorded neuron: (1) direct responses caused by activation of glutamate receptors on the recorded cell and (2) synaptically mediated responses resulting from the suprathreshold activation of presynaptic neurons. To differentiate between these two types of responses, experiments in low $\mathrm{Ca}^{2+} /$ high $\mathrm{Mg}^{2+}$ ACSF were performed (Fig. $3 a, b)$ that blocked synaptic transmission $(n=3)$. Under this condition, direct responses could only be recorded after stimulation of fields, which were restricted to the region containing the somatodendritic extensions of the recorded cell. Because of calibration of the UV flash intensity [for details see Schubert et al. (2001a)], only stimulation of perisomatic fields induced a membrane depolarization sufficient to elicit an action potential (Fig. 3a1). With increasing distance to the somatic recording site, amplitudes of flash-induced depolarizations decreased rapidly (Fig. 3a2). These direct responses followed the photostimulation almost instantaneously (Fig. $3 b$ ). Short delayto-onset times of $0.2-0.8 \mathrm{msec}$ were observed only on perisomatic stimulation. Stimulation of the remaining fields containing dendrites elicited responses with delays of 1-2.5 msec.

In normal ACSF, as for experiments in low $\mathrm{Ca}^{2+} /$ high $\mathrm{Mg}^{2+}$ solution, only perisomatic stimulation elicited an action potential (Fig. 3a1,c1). As for other cell types in various cortical layers (see Materials and Methods), in none of the layer IV spiny neurons could action potentials be elicited in fields at distances $>100$ $\mu \mathrm{m}$ from the soma. In normal ACSF, in addition to direct responses, synaptically mediated activity was evoked by stimulation of fields containing presynaptic neurons. Direct responses and synaptically mediated activity were clearly separated by their different delay-to-onset times (Fig. 3d). Within the barrel of the recorded cell, the fastest synaptically mediated responses occurred after $5 \mathrm{msec}$ after stimulus, whereas the slowest direct responses occurred at most $5 \mathrm{msec}$ after stimulus.

Excitatory synaptic inputs often consisted of two or more single EPSPs with amplitudes of $0.5-3 \mathrm{mV}$ (Fig. 3c2). These multiple EPSPs most likely resulted from activation of several presynaptic 

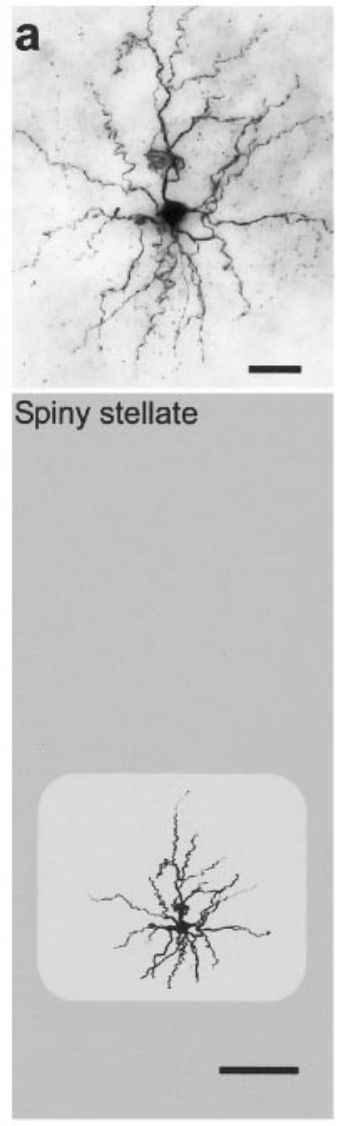
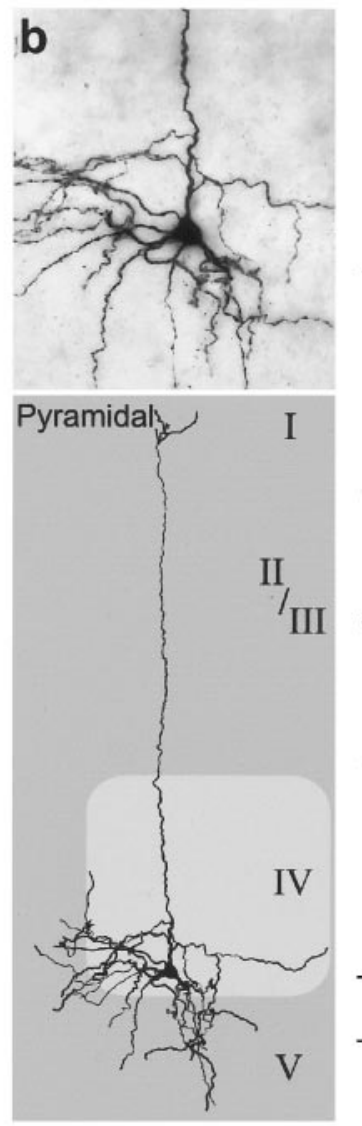
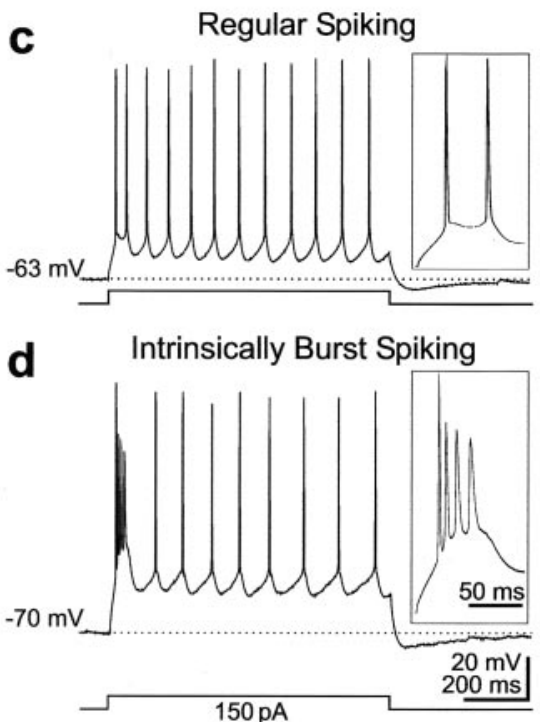

e

Pyramidal cell $\triangle$
Spiny stellate cell $\square$

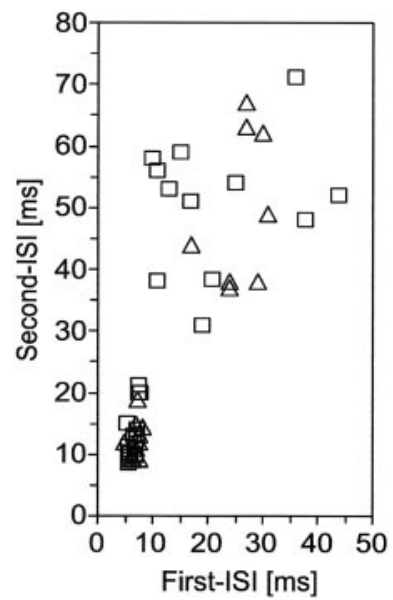

f

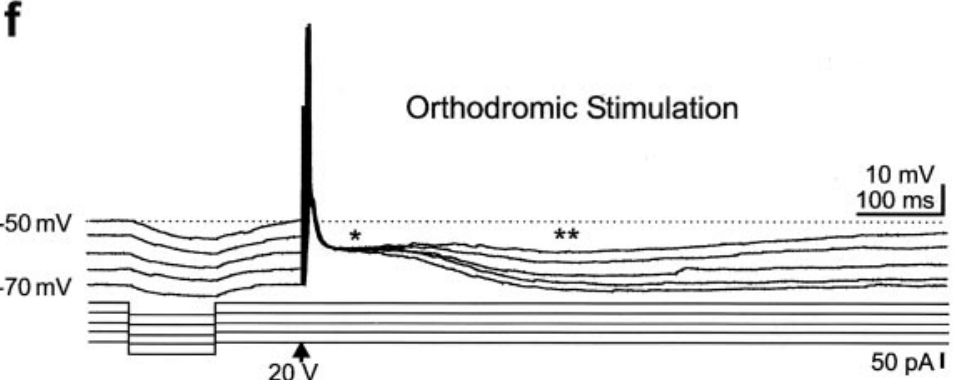

Figure 2. Morphology and electrophysiology of layer IV spiny neurons. $a, b$, Photomicrographs (scale bar, top panel, $25 \mu \mathrm{m}$ ) and somatodendritic reconstructions (scale bar, bottom panel, 100 $\mu \mathrm{m}$ ) of biocytin-stained layer IV spiny neurons. The lighter shaded areas mark the dimensions of the respective barrels. a, Spiny stellate cell with dendrites showing a spherical organization restricted to the barrel. $b$, Pyramidal cell with apical dendrite reaching layer I and basal dendrites forming a skirt-like pattern. Action potential firing pattern $(c, d)$ and correlation of first-ISI versus second-ISI (e). $f$, Synaptic responses of layer IV spiny neurons. Spiny stellate as well as star pyramidal and pyramidal cells revealed one of the following firing patterns on injection of a suprathreshold depolarizing current pulse at resting membrane potential. In regular spiking cells, depolarizing current evoked a low-frequency train of single action potentials ( $c$ ). Intrinsically bursting neurons revealed an initial high-frequency burst consisting of an action potential followed by a depolarizing afterpotential with at least two spikes of decreasing amplitude ( $d$ ). The initial burst was followed by a sequence of single action potentials.e, Correlation of first-ISI versus second-ISI revealed two clusters representing the two types of action potential firing pattern: IB firing (small cluster at bottom left) and RS firing (larger cluster at top right). Data are shown for 46 spiny neurons (28 spiny stellate cells and 18 pyramidal cells).f, Postsynaptic responses of a spiny neuron to orthodromic electrical stimulation at different membrane potentials. The stimulus elicited an action potential and an EPSP followed by a fast (asterisk) and slow (double asterisk) IPSP.

cells or of presynaptic IB neurons (Thomson, 1997). Because neurons were held at $-60 \mathrm{mV}$ during mapping, IPSPs were detected as hyperpolarizing potentials (Fig. 3c3).

For the topographic mapping of synaptic inputs onto layer IV neurons, we stimulated 450 different fields of $50 \times 50 \mu \mathrm{m}$ in size covering an area of all six cortical layers and two neighboring barrel-related columns (Fig. 1c). For quantitative analysis of the spatial distribution of synaptic inputs onto layer IV spiny neurons, we determined the percentages of fields generating synaptic inputs after photostimulation for each cortical layer and column.

\section{Intracolumnar synaptic inputs onto spiny stellate cells}

Spiny stellate cells $(n=14)$ received the vast majority of their excitatory synaptic inputs from fields inside the same barrel (Fig. $4 a$ ). On average, $52 \pm 14 \%$ of the tested fields in layer IV generated an excitatory response (Fig. $5 a$ ). In contrast, $<4 \%$ of the fields in the nongranular layers elicited an excitatory response. Three of 14 spiny stellate cells did not receive any excitatory synaptic inputs from outside the same barrel. From the remaining cells, five did not receive any synaptic inputs from supragranular layers. Of all nongranular layers, the most consistent sources for excitatory synaptic inputs onto spiny stellate cells were layers $\mathrm{Va}$ and VI ( 9 of 13 spiny stellate cells).

To quantify the average strength of excitatory inputs originating from fields in a certain layer or column, we calculated the integral of all detectable flash-induced EPSPs within a time window of 150 msec after stimulus for each trace (Fig. $5 b$ ). All traces without any detectable stimulus-related activity were excluded from this quantification. Most of the excitatory inputs originating from fields within the respective barrel consisted of multiple high-amplitude EPSPs $(0.19 \pm 0.18 \mathrm{mV} * \mathrm{sec})$, indicating extensive and strong intrabarrel coupling with other excitatory neurons. The average strength of excitatory inputs from all other layers was significantly weaker $(0.04 \pm 0.03 \mathrm{mV} * \mathrm{sec} ; p<0.01)$.

All spiny stellate cells received inhibitory inputs that originated predominantly from the same barrel (Figs. $4 a, 5 c$ ); however, the percentage of fields in layer IV delivering inhibitory synaptic inputs was variable. Some spiny stellate cells received inhibitory inputs from $>50 \%$ of the fields within their barrel $(n=2)$; others received inhibitory inputs from $<10 \%(n=5)$. Additional intracolumnar inhibitory synaptic inputs originated from lower layer III and layer Va. 


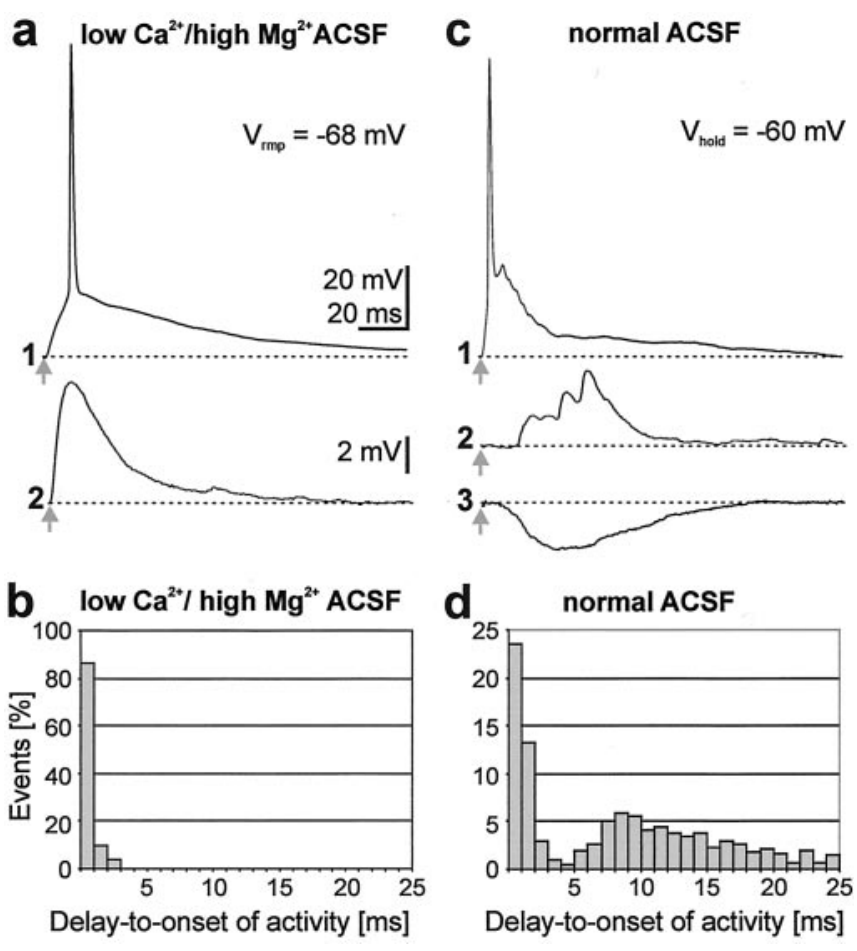

Figure 3. Nonsynaptic and synaptic responses elicited by focal caged glutamate photolysis. a, Direct postsynaptic responses recorded at resting membrane potential in ACSF containing 0.2 $\mathrm{mm} \mathrm{Ca}^{2+} / 4 \mathrm{~mm} \mathrm{Mg}^{2+}$ to block synaptic transmission. a1 shows suprathreshold response to perisomatic stimulation, and $a 2$ illustrates response to stimulation of distal dendrites. $b$, Histogram showing delay to onset of glutamate-induced responses ( $n=3$ neurons) recorded in low $\mathrm{Ca}^{2+} /$ high $\mathrm{Mg}^{2+}$ bathing solution. Note that all direct postsynaptic events appeared within the first 3 msec after stimulus. c, Synaptic responses recorded in ASCF at a holding potential of $-60 \mathrm{mV}$ after local glutamate photolysis in a perisomatic field ( $(1)$, in a remote field containing one or more synaptically connected excitatory neurons ( $(2)$, and in a field containing at least one synaptically connected inhibitory cell (c3). d, Delay-to-onset distribution of glutamate-induced responses ( $n=24$ neurons) recorded in normal ACSF. Although direct nonsynaptic responses appeared with a delay $\leq 5 \mathrm{msec}$, all synaptically mediated PSPs showed delay-to-onset latencies $>5$ msec.

\section{Intracolumnar synaptic inputs onto pyramidal cells}

In addition to their distinct morphological property of an apical dendrite, pyramidal cells $(n=10)$ showed pronounced differences in their synaptic inputs when compared with spiny stellate cells. A representative topographic map of functional connectivity of a layer IV pyramidal cell is shown in Figure $4 b$. Within the barrel, $66 \pm 15 \%$ of the fields delivered EPSPs on stimulation, indicating strong intrabarrel excitatory interactions. In contrast to spiny stellate cells, however, all pyramidal neurons received numerous excitatory inputs from nongranular layers of the same column (Fig. 5a). On average, $20 \%$ of the fields in nongranular layers generated excitatory inputs after photostimulation. Especially within the infragranular layers $\mathrm{Vb}$ and $\mathrm{VI}$ of the same column, the percentages of fields delivering excitatory inputs onto pyramidal neurons were significantly higher compared with spiny stellate cells (Vb, $p<0.01$; VI, $p<0.01$ ). Regarding the strength of intracolumnar excitatory inputs, we found no significant differences between pyramidal and spiny stellate cells (Fig. $5 b$ ). Inhibitory synaptic inputs onto pyramidal neurons, as in spiny stellate neurons, predominantly originated in layer IV as well as from lower layer III and layer Va (Figs. $4 b, 5 c$ ).

\section{Transcolumnar interactions}

Transcolumnar synaptic inputs onto layer IV spiny stellate cells were observed only rarely. Only 2 of 14 spiny stellate neurons received excitatory and inhibitory synaptic inputs arising from the neighboring barrel-related column (Fig. $6 a$ ). In contrast, 6 of 10 pyramidal neurons received numerous transcolumnar excitatory inputs. Representative topographic maps documenting transcolumnar synaptic inputs are shown in Figure 6, $a$ and $b$. On average, pyramidal cells received significantly more excitatory inputs from all layers of the neighboring column than spiny stellate cells (layer II/III, $p<0.01$; layer IV, $p<0.05$; Va, $p<0.05$; $\mathrm{Vb}, p<0.05$; VI, $p<0.01$ ) (Fig. 5a). However, if transcolumnar connectivity was present, both cell types received excitatory synaptic inputs especially from the neighboring barrel. Photostimulation in the neighboring barrel could induce excitatory synaptic inputs from up to $20 \%$ of the fields. The strength of these excitatory transcolumnar inputs was similar for both cell types (Fig. $5 b$ ). As illustrated in Figure $6 c$, excitatory transbarrel inputs usually consisted of multiple EPSPs. However, the average strength of these synaptic inputs $(0.05 \pm 0.03 \mathrm{mV} * \mathrm{sec})$ did not reach the strength of excitatory intrabarrel connections. Inhibitory synaptic inputs from the neighboring column were altogether rare but could be observed in two spiny stellate and five pyramidal cells. These cells received inhibitory inputs mainly from the neighboring barrel, where $2-5 \%$ of the fields generated IPSPs after photostimulation, as well as occasionally from layer II/III and Vb (Fig. $5 c$ ).

Layer IV neurons receiving transcolumnar synaptic inputs did not show a preferred location within the barrel. The spatial dimensions of the proximal dendrites in these neurons were similar to those observed in layer IV cells receiving no transcolumnar input, indicating that a different dendritic geometry may not account for the observed interactions.

\section{Does functional connectivity correlate with intrinsic firing patterns?}

In layer $\mathrm{V}$, functional connectivity of excitatory neurons correlates with the active membrane properties of the cell and its morphology (Schubert et al., 2001a). In the present study, however, layer IV spiny neurons showed no correlation between functional connectivity and the firing pattern of the cell. Neither within nor across the two identified morphological groups of layer IV spiny neurons did IB cells differ significantly from RS cells in terms of their excitatory or inhibitory functional connectivity (data not shown).

\section{Discussion}

Using a combination of in vitro whole-cell recordings, detailed mapping of excitatory and inhibitory synaptic inputs, and morphological reconstruction, we were able to demonstrate a cell type-specific input onto layer IV spiny neurons in rat barrel cortex. Whereas synaptic inputs onto spiny stellate neurons originate predominantly from the same barrel, layer IV pyramidal neurons receive additional excitatory and inhibitory synaptic inputs from supragranular and infragranular layers of the same barrel column and from the adjacent barrel (Fig. 7). Our data imply that spiny stellate and pyramidal neurons in rat barrel cortex can be differentiated by their distinct intracortical synaptic inputs, indicating that the somatodendritic structure of a cortical neuron correlates with a distinct role in intracortical sensory information processing. In this processing, a strong local component is likely to be mediated by spiny stellate neurons, whereas pyramidal cells additionally contribute in a more global manner. The coexistence of these two cell types in layer IV is not unique for the rat somatosensory cortex. Other species, including primates, as well as other sensory cortices also show this feature (Jones, 1975; Tarczy-Hornoch et al., 1998; Smith and Populin, 2001; 

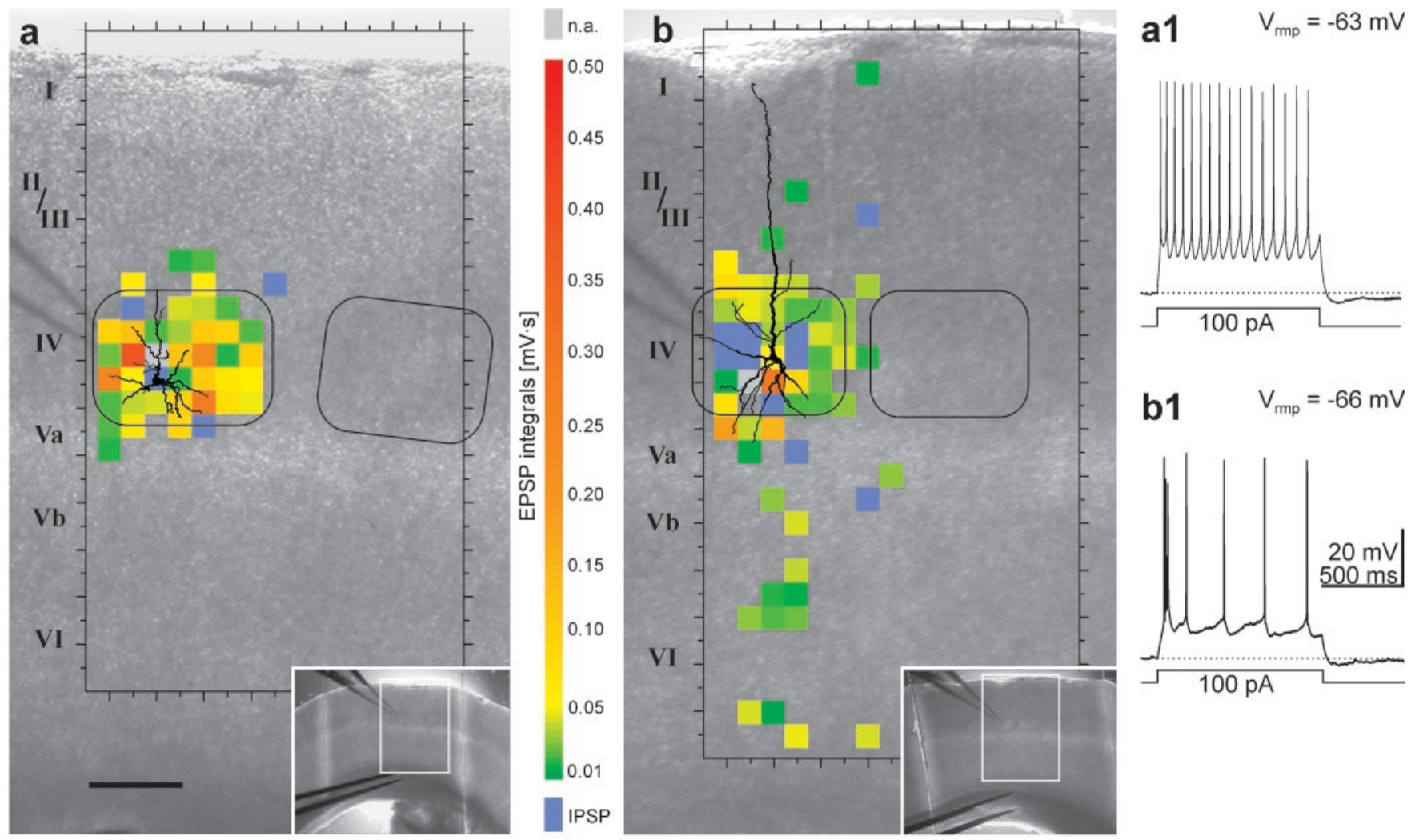

Figure 4. Topographic maps of functional connectivity of layer IV spiny neurons. The somatodendritic reconstruction of a recorded spiny stellate $(a)$ and a pyramidal cell $(b)$ as well as the respective topographic maps of their synaptic inputs were superimposed on the photomicrographs of the native slices. The topographic maps illustrate integrals of recorded EPSPs within 150 msec after stimulus ( green to red) and fields of origin for IPSPs (blue). Note that for simplification, in fields where stimulation evoked EPSPs as well as IPSPS, only the IPSP is represented (blue). Fields given in gray were excluded from analysis because of a strong temporal interaction among direct postsynaptic activation, action potential generation, and synaptic events. Stimulated fields that did not induce any response are transparent. The outer black frames indicate the extent of the investigated area; the rounded black rectangles highlight the dimensions of the relevant barrels. Insets show the enlarged cortical area within the slice (white frame). Action potential firing patterns on injection of a suprathreshold depolarizing current pulse at $V_{\text {rmp }}$ are illustrated in $a 1$ and $b 1$. Scale bar, $200 \mu \mathrm{m}$.

Yabuta et al., 2001). Interestingly, a correlation between the morphology of a cell and its role in cortical signal processing has recently been documented in the primary visual cortex of macaque monkey as well (Yabuta et al., 2001), suggesting that cell type-specific parallel pathways might be a more general feature of cortical circuitry organization. These findings promote the idea that columnar circuits possess a common structural design (Mountcastle, 1997). They further suggest that mechanisms of top-down modulation and horizontal integration contribute to signal processing in layer IV (Harris et al., 2001), as already shown for feedforward excitation and inhibition (Miller et al., 2001b).

\section{Methodological considerations}

The method as such was described and discussed in detail in a previous publication (Schubert et al., 2001a). The main conclusion is that monosynaptic inputs to identified neurons are mapped with a (sub-)laminar resolution by stimulating neurons via photolytic release of caged glutamate. The fact that we use in vitro preparations necessitates the caveat that slicing of the brain results in loss of a substantial proportion of cortical circuitry. However, our goal to describe local columnar and neighboring transcolumnar pathways should not be compromised significantly, because we and others have shown previously that a great number of even more distant projections remain intact (Burkhalter, 1989; Staiger et al., 1999). Another issue relates to the possi- bility that cortical functional connectivity in adolescent rats, as investigated here, partially represents a transient, developmental phenomenon. However, previous studies in somatosensory (Nicolelis et al., 1991; Miller et al., 2001a) and visual cortex (Borrell and Callaway, 2002) indicate that exuberant axonal connections exist only during the very early stages of ontogenesis and reach their mature pattern after the first postnatal week. In fact, at postnatal day 20 , the general pattern of synaptic inputs onto spiny neurons, as revealed in this study, is likely to represent an adultlike stage of functional connectivity in rat somatosensory cortex (Nicolelis et al., 1991; Miller et al., 2001a).

\section{Local versus global information processing in layer IV barrel cortex}

Layer IV spiny neurons in rodent barrel cortex are the main target of thalamocortical afferents originating from neurons in the ventroposteromedial nucleus (Benshalom and White, 1986; Staiger et al., 1996). Whether layer IV barrels are interconnected via excitatory and inhibitory pathways (Armstrong-James et al., 1991; Fox, 1994; Gil et al., 1999) or function as an array of independent, parallel processors of afferent information (Goldreich et al., 1999; Kim and Ebner, 1999) is highly controversial. Previous extracellular tracing studies in rodent barrel cortex have demonstrated only poor direct barrel-to-barrel connections, suggesting that layer IV barrels are essentially isolated from transcolumnar horizontal interactions (Kim and Ebner, 1999). In con- 
a

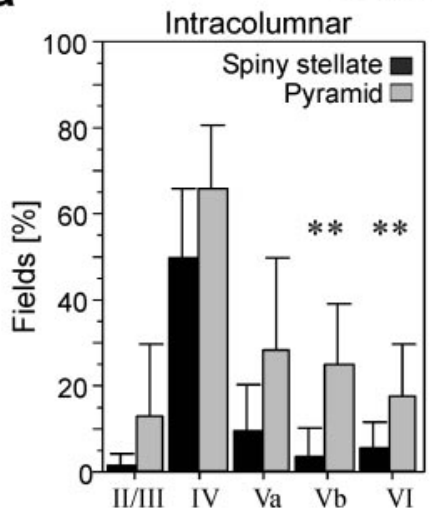

Excitatory inputs

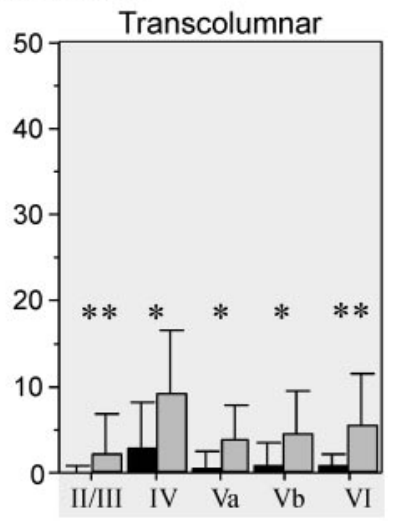

b
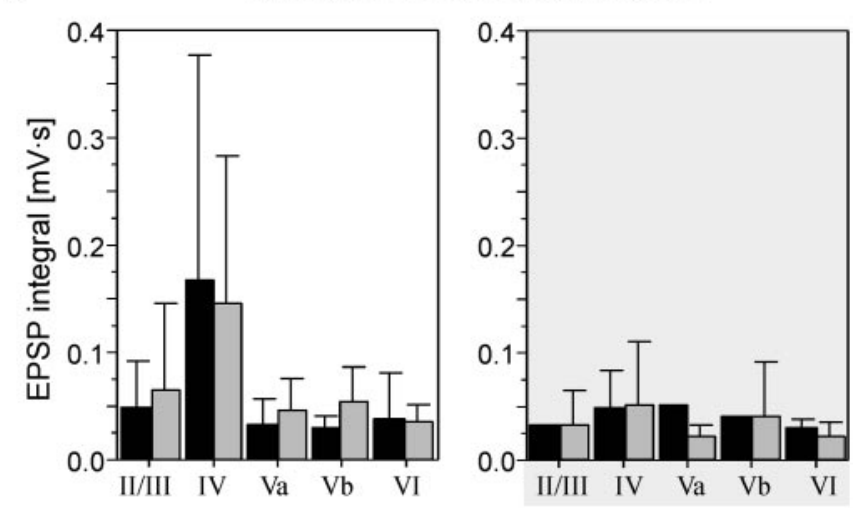

C

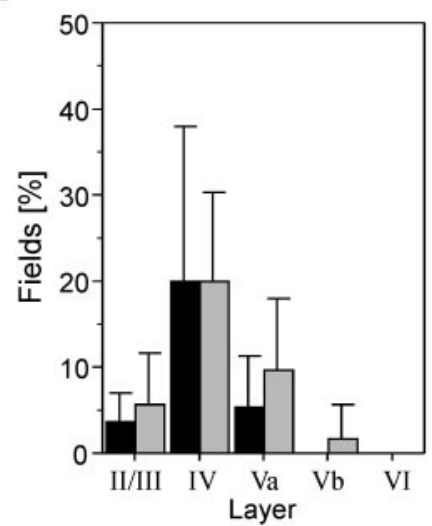

Inhibitory inputs

Figure 5. Spatial distribution of synaptic inputs onto layer IV spiny neurons. $a$, Percentages of stimulated presynaptic fields delivering intracolumnar and transcolumnar excitatory synaptic inputs onto layer IV spiny stellate cells (black bars, $n=11$ ) and pyramidal neurons (shaded bars, $n=8) . b$, Mean strength of excitatory intracolumnar and transcolumnar synaptic inputs. c, Percentages of stimulated presynaptic fields delivering inhibitory synaptic inputs. Note that in $a$ and c scales for transcolumnar inputs are enlarged. Data are means \pm SD. Asterisks indicate significant differences between the two cell groups: ${ }^{*} p<0.05$ and ${ }^{* *} p<0.01$.

trast, in vivo recordings strongly indicate that surround receptive fields of layer IV barrel neurons are predominantly generated intracortically by barrel-to-barrel interactions (ArmstrongJames et al., 1991; Fox, 2002).

We demonstrate that layer IV spiny neurons may act as local or global processors, depending on their somatodendritic morphology. Although spiny stellate cells function predominantly in intrabarrel information processing, layer IV pyramidal neurons

also receive transbarrel inputs and participate directly in translaminar and transcolumnar circuits. This finding is in good agreement with a recent in vivo study (Brecht and Sakmann, 2002) in which pyramidal cells showed stronger responses to multiwhisker stimulation than spiny stellate cells. Support for this conclusion comes also from other previous experimental studies: $\sim 85 \%$ of the excitatory synaptic inputs onto layer IV spiny stellate cells originate from intracortical sources (Benshalom and White, 1986), predominantly from other spiny stellate neurons in the same barrel (Feldmeyer et al., 1999), indicating that a local network of spiny stellate cells operates in intrabarrel information processing and serves to separate the representations of single whiskers (Petersen and Sakmann, 2001). The axonal projection of layer IV spiny stellate cells in sensory cortex is relatively narrow and seems to be restricted primarily to a single cortical column (Harris and Woolsey, 1983; Lübke et al., 2000). In rat barrel cortex, short-range axonal connections within a single barrel are highly reliable, and unitary EPSPs can be sufficiently depolarizing to elicit an action potential in the postsynaptic cell (Feldmeyer et al., 1999). Our observations on spiny stellate neurons are in good agreement with these previous reports. More than $80 \%$ of the intracolumnar excitatory inputs onto spiny stellate neurons originated from adjacent neurons within the same barrel. These intrabarrel connections represent the strongest synaptic inputs that we observed. They could be the critical component of circuits extracting the physical parameters of sensory stimuli encoded by individual sets of peripheral receptors. The second major intracortical source for excitatory inputs on spiny neurons in layer IV is known to be layer VI (Ahmed et al., 1994; Zhang and Deschênes, 1997). In our experiments, however, this layer VI to layer IV connection turned out to be not very prominent in both investigated cells types. This probably relates to the weak synaptic efficacy of these excitatory inputs (Tarczy-Hornoch et al., 1999).

Spiny stellate cells receive a weaker intracolumnar and transcolumnar synaptic input, possibly because they lack an apical dendrite. Morphologically, pyramidal neurons show a more extended and vertically polarized dendritic tree, which may explain their responses to intracolumnar inputs from extragranular neurons and transcolumnar inputs from the neighboring barrel. Layer IV pyramidal neurons might receive synaptic inputs from neurons located in the neighboring barrel mostly via axonal connections ascending to supragranular layers. Thomson and Deuchars (1994) suggested that synaptic connections even between closely spaced neurons might involve their distal apical dendrite (Thomson and Deuchars, 1994). Recently, Lübke et al. (2000) demonstrated in rat barrel cortex that the axonal projections of layer IV (star) pyramidal neurons to supragranular layers fan out in a clustered manner, and a few of these collaterals innervate adjacent cortical columns. Postsynaptic targets of this layer IV to layer II/III projection are small caliber dendritic shafts or spines (Lübke et al., 2000) that could belong to layer IV pyramidal cells. They could be the critical component of circuits modulating local signal processing with horizontal and top-down information, thus providing the context of what is perceived by neighboring receptors and processed by hierarchically higher layers or areas. According to our results, top-down information is provided mainly by neurons in the infragranular layers. However, we occasionally found excitatory inputs originating also from the supragranular layers, especially for the layer IV pyramidal cells. The presumably low number of neurons involved in this layer II/III to layer IV connection may explain why such an interaction could not yet be revealed in paired recording studies (Feldmeyer et al., 2002; Thomson et al., 2002). 

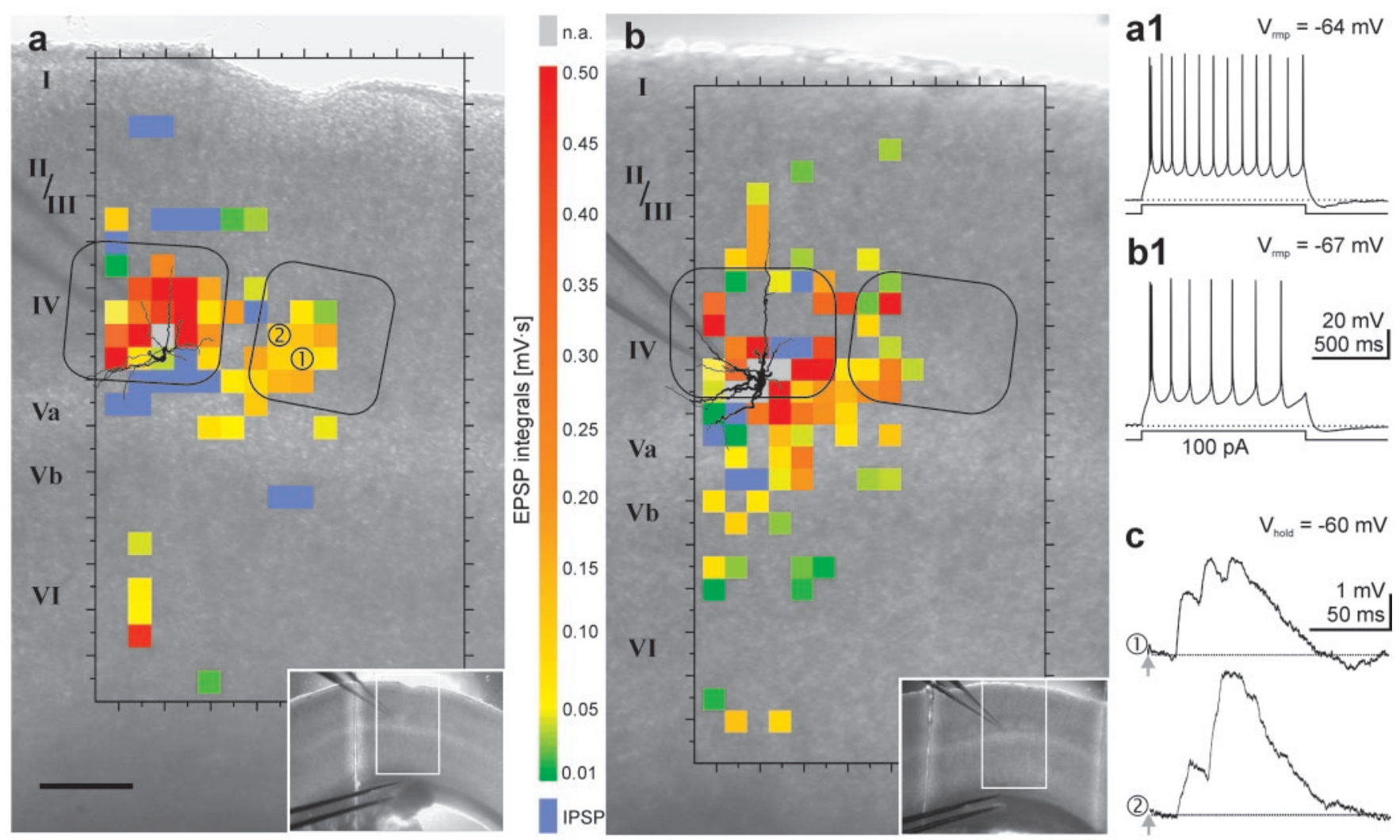

Figure 6. Layer IV spiny neurons show direct barrel-to-barrel interactions. Topographic maps of excitatory and inhibitory synaptic inputs onto a layer IV spiny stellate cell ( $a$ ) and a pyramidal cell (b). Insets show the enlarged cortical area within the slice (white frame). Action potential firing patterns on injection of a suprathreshold depolarizing current pulse at $V_{\text {rmp }}$ are illustrated in $a 1$ and b1. c, EPSPs recorded at $V_{\text {hold }}=-60 \mathrm{mV}$ on stimulation of fields in the neighboring barrel at positions indicated in $a$. Scale bar, $200 \mu \mathrm{m}$.

Inhibitory synaptic circuits in layer IV are not well defined. A small percentage $(10 \%)$ of all inhibitory inputs originated from the neighboring column (cf. Salin and Prince, 1996), and these could contribute to transbarrel inhibition during cross-whisker stimulation (Simons and Carvell, 1989). More frequent inhibitory synaptic inputs onto layer IV spiny neurons originated from intracolumnar sources (Salin and Prince, 1996), and these inputs may sculpture the receptive fields of the excitatory neurons or synchronize the activity of neuronal ensembles within a barrel-related column. Under in vivo conditions, the strongest IPSPs are consistently evoked by the primary vibrissa (Moore and Nelson, 1998), reflecting the prominent intrabarrel inhibition demonstrated in the present study. Morphological (Kisvárday et al., 1985) as well as electrophysiological (TarczyHornoch et al., 1998) studies in cat visual cortex demonstrated that these local inhibitory synaptic inputs onto layer IV spiny neurons mainly originate from small basket cells. In rat barrel cortex, virtually all layer IV GABAergic neurons, which certainly include a population of basket cells, receive a strong thalamocortical input and project locally within their own barrel, thereby generating feedforward inhibition (Porter et al., 2001).
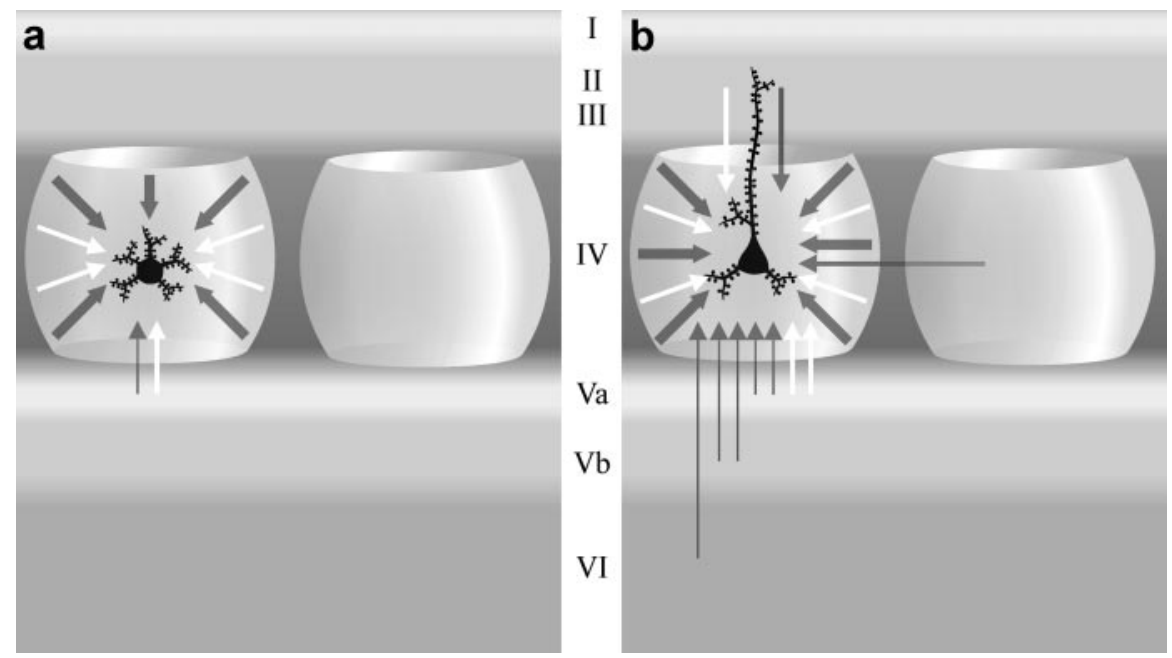

Figure 7. Schematic illustration of excitatory and inhibitory intracolumnar and transcolumnar synaptic inputs onto layer IV spiny neurons in rodent barrel cortex. Excitatory synaptic inputs are shown in gray; inhibitory inputs are shown in white. The density of synaptic inputs is represented by the number of arrows (1 gray arrow: 10\% of fields generated EPSPs; 1 white arrow: $5 \%$ of fields generated IPSPs). The average strength of excitatory synaptic inputs is represented by the thickness of the arrows (thin arrow: $<0.05 \mathrm{mV} * \mathrm{sec}$; medium arrow: $0.05-0.1 \mathrm{mV} * \mathrm{sec}$; thick arrow: $>0.1 \mathrm{mV} * \mathrm{sec})$. Although spiny stellate cells receive predominantly intrabarrel synaptic inputs $(a)$, layer IV pyramidal neurons are additionally innervated from supragranular and infragranular layers and from the neighboring barrel $(b)$.

\section{Functional implications}

Intracortical connections undergo rapid experience-dependent modifications in their synaptic strength. Altered sensory experience ["whisker pairing" (Diamond et al., 1993) or "univibrissa rearing" (Fox, 1994)] induces massive modifications in the re- 
ceptive field properties of layer IV cells in adult rat barrel cortex. These modifications depend to a large degree on intracortical pathways within and between barrels (Armstrong-James, 1995; Fox, 2002), most likely with a contribution of long-term potentiation- and long-term depression-like mechanisms (Feldman, 2000; Fox, 2002). Because layer IV pyramidal neurons are the main target of synaptic inputs from the neighboring barrel, experience-dependent changes in barrel-to-barrel interactions may be mediated predominantly by changes in the efficacy of synaptic inputs onto layer IV pyramidal neurons. These connections were shown to play an important role in experiencedependent and lesion-induced reorganization at the cortical level (Armstrong-James et al., 1991, 1994; Finnerty et al., 1999; Fox, 2002). Subthreshold inputs originating from neighboring barrelrelated columns, together with thalamocortical connections ( $\mathrm{Pe}-$ tersen and Diamond, 2000), may contribute to receptive field plasticity and reorganization of cortical maps when intracortical inhibition is reduced (Moore and Nelson, 1998; Moore et al., 1999). The proposed circuits for local sensory signal processing and global integration of horizontal and top-down information are considered to represent mechanisms that enable sensory cortices to participate in the formation of behaviorally relevant memories (Harris et al., 2001). An important goal for further studies remains to show how these cell type-specific circuits interact and under what behavioral conditions they are used.

\section{References}

Ahmed B, Anderson JC, Douglas RJ, Martin KA, Nelson JC (1994) Polyneuronal innervation of spiny stellate neurons in cat visual cortex. J Comp Neurol 341:39-49.

Angulo MC, Staiger JF, Rossier J, Audinat E (1999) Developmental synaptic changes increase the range of integrative capabilities of an identified excitatory neocortical connection. J Neurosci 19:1566-1576.

Armstrong-James M (1995) . The nature and plasticity of sensory processing within adult rat barrel cortex. In: Cerebral cortex (Jones EG, Diamond IT, eds), pp 333-373. New York: Plenum.

Armstrong-James M, Callahan CA, Friedman MA (1991) Thalamo-cortical processing of vibrissal information in the rat. I. Intracortical origins of surround but not centre-receptive fields of layer IV neurones in the rat S1 barrel field cortex. J Comp Neurol 303:193-210.

Armstrong-James M, Fox K, Das-Gupta A (1992) Flow of excitation within rat barrel cortex on striking a single vibrissa. J Neurophysiol 68:1345-1358.

Armstrong-James M, Diamond ME, Ebner FF (1994) An innocuous bias in whisker use in adult rats modifies receptive fields of barrel cortex neurons. J Neurosci 14:6978-6991.

Benshalom G, White EL (1986) Quantification of thalamocortical synapses with spiny stellate neurons in layer IV of mouse somatosensory cortex. J Comp Neurol 253:303-314.

Borrell V, Callaway EM (2002) Reorganization of exuberant axonal arbors contributes to the development of laminar specificity in ferret visual cortex. J Neurosci 22:6682-6695.

Brecht M, Sakmann B (2002) Dynamic representation of whisker deflection by synaptic potentials in spiny stellate and pyramidal cells in the barrels and septa of layer 4 rat somatosensory cortex. J Physiol (Lond) 543:49-70.

Burkhalter A (1989) Intrinsic connections of rat primary visual cortex: laminar organization of axonal projections. J Comp Neurol 279:171-186.

Callaway EM, Katz LC (1993) Photostimulation using caged glutamate reveals functional circuitry in living brain slices. Proc Natl Acad Sci USA 90:7661-7665.

Chagnac-Amitai Y, Connors BW (1989) Synchronized excitation and inhibition driven by intrinsically bursting neurons in neocortex. J Neurophysiol 62:1149-1162.

Connors BW, Gutnick MJ (1990) Intrinsic firing patterns of diverse neocortical neurons. Trends Neurosci 13:99-104.

Diamond ME, Armstrong-James M, Ebner FF (1993) Experiencedependent plasticity in adult rat barrel cortex. Proc Natl Acad Sci USA 90:2082-2086.

Diamond ME, Huang W, Ebner FF (1994) Laminar comparison of somatosensory cortical plasticity. Science 265:1885-1888.
Feldman DE (2000) Timing-based LTP and LTD at vertical inputs to layer II/III pyramidal cells in rat barrel cortex. Neuron 27:45-56.

Feldmeyer D, Sakmann B (2000) Synaptic efficacy and reliability of excitatory connections between the principal neurones of the input (layer 4) and output layer (layer 5) of the neocortex. J Physiol (Lond) 525:31-39.

Feldmeyer D, Egger V, Lübke J, Sakmann B (1999) Reliable synaptic connections between pairs of excitatory layer 4 neurones within a single "barrel" of developing rat somatosensory cortex. J Physiol (Lond) 521:169-190.

Feldmeyer D, Lübke J, Silver RA, Sakmann B (2002) Synaptic connections between layer 4 spiny neurone-layer $2 / 3$ pyramidal cell pairs in juvenile rat barrel cortex: physiology and anatomy of interlaminar signalling within a cortical column. J Physiol (Lond) 538:803-822.

Finnerty GT, Roberts LS, Connors BW (1999) Sensory experience modifies the short-term dynamics of neocortical synapses. Nature 400:367-371.

Fox K (1994) The cortical component of experience-dependent synaptic plasticity in the rat barrel cortex. J Neurosci 14:7665-7679.

Fox K (2002) Anatomical pathways and molecular mechanisms for plasticity in the barrel cortex. Neuroscience 111:799-814.

Gil Z, Connors BW, Amitai Y (1999) Efficacy of thalamocortical and intracortical synaptic connections: quanta, innervation, and reliability. Neuron 23:385-397.

Gilbert CD, Das A, Ito M, Kapadia MK, Westheimer G (1996) Cortical dynamics and visual perception. Cold Spring Harb Symp Quant Biol 61:105-113.

Goldreich D, Kyriazi HT, Simons DJ (1999) Functional independence of layer IV barrels in rodent somatosensory cortex. J Neurophysiol 82:1311-1316.

Harris JA, Petersen RS, Diamond ME (2001) The cortical distribution of sensory memories. Neuron 30:315-318.

Harris RM, Woolsey TA (1983) Computer-assisted analyses of barrel neuron axons and their putative synaptic contacts. J Comp Neurol 220:63-79.

Jones EG (1975) Varieties and distribution of non-pyramidal cells in the somatic sensory cortex of the squirrel monkey. J Comp Neurol 160:205-267.

Jones EG, Diamond IT (1995) The barrel cortex of rodents. New York: Plenum.

Kim U, Ebner FF (1999) Barrels and septa: separate circuits in rat barrels field cortex. J Comp Neurol 408:489-505.

Kisvárday ZF, Martin KA, Whitteridge D, Somogyi P (1985) Synaptic connections of intracellularly filled clutch cells: a type of small basket cell in the visual cortex of the cat. J Comp Neurol 241:111-137.

Kötter R, Staiger JF, Zilles K, Luhmann HJ (1998) Analyzing functional connectivity in brain slices by a combination of infrared video microscopy, flash photolysis of caged compounds and scanning methods. Neuroscience 86:265-277.

Laaris N, Carlson GC, Keller A (2000) Thalamic-evoked synaptic interactions in barrel cortex revealed by optical imaging. J Neurosci 20:1529-1537.

Lübke J, Egger V, Sakmann B, Feldmeyer D (2000) Columnar organization of dendrites and axons of single and synaptically coupled excitatory spiny neurons in layer 4 of the rat barrel cortex. J Neurosci 20:5300-5311.

Miller B, Blake NM, Erinjeri JP, Reistad CE, Sexton T, Admire P, Woolsey TA (2001a) Postnatal growth of intrinsic connections in mouse barrel cortex. J Comp Neurol 436:17-31.

Miller KD, Pinto DJ, Simons DJ (2001b) Processing in layer 4 of the neocortical circuit: new insights from visual and somatosensory cortex. Curr Opin Neurobiol 11:488-497.

Moore CI, Nelson SB (1998) Spatio-temporal subthreshold receptive fields in the vibrissa representation of rat primary somatosensory cortex. J Neurophysiol 80:2882-2892.

Moore CI, Nelson SB, Sur M (1999) Dynamics of neuronal processing in rat somatosensory cortex. Trends Neurosci 22:513-520.

Mountcastle VB (1997) The columnar organization of the neocortex. Brain 120:701-722.

Nicolelis MA, Chapin JK, Lin CS (1991) Ontogeny of corticocortical projections of the rat somatosensory cortex. Somatosens Mot Res 8:193-200.

Paxinos G, Watson C (1998) The rat brain in stereotaxic coordinates. San Diego: Academic.

Petersen CC, Sakmann B (2000) The excitatory neuronal network of rat layer 4 barrel cortex. J Neurosci 20:7579-7586.

Petersen CC, Sakmann B (2001) Functionally independent columns of rat somatosensory barrel cortex revealed with voltage-sensitive dye imaging. J Neurosci 21:8435-8446. 
Petersen RS, Diamond ME (2000) Spatial-temporal distribution of whisker-evoked activity in rat somatosensory cortex and the coding of stimulus location. J Neurosci 20:6135-6143.

Porter JT, Johnson CK, Agmon A (2001) Diverse types of interneurons generate thalamus-evoked feedforward inhibition in the mouse barrel cortex. J Neurosci 21:2699-2710.

Salin PA, Prince DA (1996) Electrophysiological mapping of GABAA receptor-mediated inhibition in adult rat somatosensory cortex. J Neurophysiol 75:1589-1600.

Sawatari A, Callaway EM (2000) Diversity and cell type specificity of local excitatory connections to neurons in layer $3 \mathrm{~B}$ of monkey primary visual cortex. Neuron 25:459-471.

Schubert D, Staiger JF, Cho N, Kötter R, Zilles K, Luhmann HJ (2001a) Layer-specific intracolumnar and transcolumnar functional connectivity of layer V pyramidal cells in rat barrel cortex. J Neurosci 21:3580-3592.

Schubert D, Staiger JF, Kötter R, Zilles K, Luhmann HJ (2001b) Intracortical synaptic inputs onto layer IV spiny neurons in rat somatosensory cortex. Soc Neurosci Abstr 27:393.15.

Simons DJ (1978) Response properties of vibrissa units in rat SI somatosensory neocortex. J Neurophysiol 41:798-820.

Simons DJ, Carvell GE (1989) Thalamocortical response transformation in the rat vibrissa/barrel system. J Neurophysiol 61:311-330.

Simons DJ, Woolsey TA (1984) Morphology of Golgi-Cox-impregnated barrel neurons in rat SmI cortex. J Comp Neurol 230:119-132.

Smith PH, Populin LC (2001) Fundamental differences between the thalamocortical recipient layers of the cat auditory and visual cortices. J Comp Neurol 436:508-519.

Staiger JF, Zilles K, Freund TF (1996) Distribution of GABAergic elements postsynaptic to ventroposteromedial thalamic projections in layer IV of rat barrel cortex. Eur J Neurosci 8:2273-2285.
Staiger JF, Kötter R, Zilles K, Luhmann HJ (1999) Connectivity in the somatosensory cortex of the adolescent rat: an in vitro biocytin study. Anat Embryol 199:357-365.

Staiger JF, Kötter R, Zilles K, Luhmann HJ (2000) Laminar characteristics of functional connectivity in rat barrel cortex revealed by stimulation with caged-glutamate. Neurosci Res 37:49-58.

Tarczy-Hornoch K, Martin KA, Jack JJ, Stratford KJ (1998) Synaptic interactions between smooth and spiny neurones in layer 4 of cat visual cortex in vitro. J Physiol (Lond) 508:351-363.

Tarczy-Hornoch K, Martin KA, Stratford KJ, Jack JJ (1999) Intracortical excitation of spiny neurons in layer 4 of cat striate cortex in vitro. Cereb Cortex 9:833-843.

Thomson AM (1997) Activity-dependent properties of synaptic transmission at two classes of connections made by rat neocortical pyramidal axons in vitro. J Physiol (Lond) 502:131-147.

Thomson AM, Deuchars J (1994) Temporal and spatial properties of local circuits in neocortex. Trends Neurosci 17:119-126.

Thomson AM, West DC, Wang Y, Bannister AP (2002) Synaptic connections and small circuits involving excitatory and inhibitory neurons in layers 2-5 of adult rat and cat neocortex: triple intracellular recordings and biocytin labelling in vitro. Cereb Cortex 12:936-953.

Woolsey TA, Van der Loos H (1970) The structural organization of layer IV in the somatosensory region (SI) of mouse cerebral cortex. The description of a cortical field composed of discrete cytoarchitectonic units. Brain Res 17:205-242.

Yabuta NH, Sawatari A, Callaway EM (2001) Two functional channels from primary visual cortex to dorsal visual cortical areas. Science 292:297-300.

Zhang ZW, Deschênes M (1997) Intracortical axonal projections of lamina VI cells of the primary somatosensory cortex in the rat: a single-cell labeling study. J Neurosci 17:6365-6379. 